\title{
Genetic variation of IncRNA GAS5 contributes to the development of lung cancer
}

\author{
Weihao Li', ${ }^{1,}$, Kai Huang ${ }^{2, *}$, Fengbiao Wen ${ }^{1}$, Guanghui Cui ${ }^{1}$, Haizhou Guo ${ }^{1}$ and Song \\ Zhao $^{1}$ \\ ${ }^{1}$ Department of Thoracic Surgery, The First Affiliated Hospital of Zhengzhou University, Zhengzhou, Henan 450052, P.R. China \\ ${ }^{2}$ Department of Oncology, The First Affiliated Hospital of Zhengzhou University, Zhengzhou, Henan 450052, P.R. China \\ *These authors have contributed equally to this work \\ Correspondence to: Song Zhao, email: zhao_song@aliyun.com \\ Keywords: lung cancer, IncRNA, GAS5, susceptibility \\ Received: May 18,2017 Accepted: June 27, $2017 \quad$ Published: August 03, 2017 \\ Copyright: Li et al. This is an open-access article distributed under the terms of the Creative Commons Attribution License 3.0 \\ (CC BY 3.0), which permits unrestricted use, distribution, and reproduction in any medium, provided the original author and source \\ are credited.
}

\section{ABSTRACT}

Lung cancer remains the leading cause of cancer-related deaths throughout the world. In spite of great effort for the research of carcinogenesis, the molecular mechanisms of lung cancer remain unclear. In current study, we investigated the possible association between susceptibility of lung cancer and GAS5 rs145204276, which showed contradictory roles in carcinogenesis of colorectal cancer and hepatocellular carcinoma. We found that the del allele was significantly associated with $21 \%$ decreased risk of lung cancer $(\mathrm{OR}=0.79 ; 95 \% \mathrm{CI}=0.66-0.93 ; \mathrm{P}$ value $=$ $0.006)$. Compared with the genotype ins/ins, both the genotype ins/del (OR=0.78; $95 \% \mathrm{CI}=0.62-0.99)$ and $\mathrm{del} / \mathrm{del}(\mathrm{OR}=0.59 ; 95 \% \mathrm{CI}=0.39-0.89)$ showed decreased susceptibility of lung cancer. Real-time PCR analysis found that the expression levels of IncRNA GAS5 in lung cancer tissues were significantly lower than those in the corresponding normal tissues $(P<0.01)$. Also the relative GAS5 expression level in samples with del/del genotype was significantly higher than that in samples with ins/del and ins/ins genotype $(P<0.01)$. Taken together, our findings provided strong evidence for the hypothesis that GAS5 rs145204276 were significantly associated with the susceptibility of lung cancer, and GAS5 functions as a tumor suppressor in carcinogenesis of lung cancer.

\section{INTRODUCTION}

Lung cancer ranks the leading cause of cancer death among males in both more and less developed countries [1-3]. Although rates are now decreasing in most of these countries, they are increasing in countries where smoking uptake occurred later (e.g., China) $[1,2,4]$. According to the report of National Office for Cancer Prevention and Control of China, the estimated annual new lung cancer cases was 733.3 thousands, and the new deaths was 610.2 thousands [5]. This mainly caused the increasing smoking rate, which has been defined as one of the behavioral risk factors for many chronic diseases $[6,7]$. To date, in spite of great effort for the research of carcinogenesis, the molecular mechanisms of lung cancer remain unclear.

Recently, the dysregulation of long non-coding RNAs (lncRNAs), which are longer than 200 nucleotides and cannot be translated, has been identified in a variety of cancers due to their critical role in the regulation of cellular processes [8-10]. The lncRNA growth arrest special 5 (GAS5), a pivotal tumor suppressor long noncoding RNA in human cancers, has been identified to be involved in carcinogenesis progress of several cancers, including breast cancer, prostate cancer, hepatocellular carcinoma, and colorectal cancer [11-13]. Tao et al identified that GAS5 rs145204276 could increase the expression of GAS5, and then the risk of hepatocellular 
carcinoma [13]. However, Zheng et al found that the allele del of rs 145204276 was significantly associated with $21 \%$ decreased risk of colorectal cancer. These finding raised the concern of the differential roles of lncRNA GAS5 in carcinogenesis of different cancer types. To clarify the potential role of GAS5 rs145204276, a deletion allele of a 5-base pair del polymorphism in the promoter region of GAS5, we conducted this case-control study among a Chinese population, and investigated the possible association between GAS5 rs145204276 and susceptibility of lung cancer.

\section{RESULTS}

\section{Characteristic of the study population}

The distribution of selected characteristics between lung cancer patients and control subjects is shown in Table 1 . In total, there were 600 cases and 600 controls included in this case control study. No significant differences were observed between cases and controls for age $(\mathrm{P}=0.620)$ and gender $(\mathrm{P}=0.691)$, which indicates satisfactory matching of controls by age and gender. While a significant difference were observed for the distribution of Smoking status $(\mathbf{P}<\mathbf{0 . 0 0 1})$, which reveals lung cancer patients are more likely to be smokers.

\section{The associations of GAS5 rs145204276 with lung cancer susceptibility}

The observed genotypic frequencies of rs145204276 in the controls were in Hardy-Weinberg equilibrium (P > $0.05)$. Table 2 presents the association between GAS5 rs 145204276 and susceptibility of lung cancer. The allele del was significantly associated with $21 \%$ decreased risk of lung cancer $(\mathrm{OR}=0.79 ; 95 \% \mathrm{CI}=0.66-0.93 ; \mathrm{P}$ value $=$ 0.006).

Compared with the genotype ins/ins, both the genotype ins/del $(\mathrm{OR}=0.78 ; 95 \% \mathrm{CI}=0.62-0.99)$ and $\mathrm{del} /$ del $(\mathrm{OR}=0.59 ; 95 \% \quad \mathrm{CI}=0.39-0.89)$ showed decreased susceptibility of lung cancer. When analyzed in both dominant and recessive model, the results were still significant.

\section{Relative expression of GAS5}

Next, we further examined the expression of GAS5 in lung cancer and adjacent tissue samples with different genotypes. As shown in Figure 1, the expression levels of lncRNA GAS5 in lung cancer tissues were significantly lower than those in the corresponding normal tissues $(\mathrm{P}<0.01$, Figure 1A). Also the relative GAS5 expression level in samples with del/del genotype was significantly higher than that in samples with ins/del and ins/ins genotype $(\mathrm{P}<0.01$, Figure $1 \mathrm{~B})$.

\section{DISCUSSION}

Increasing evidence revealed that abnormal expression of GAS5 is involved in many kinds of cancers [14]. The circulating GAS5 could be used as a novel biomarker for the diagnosis of non-small cell lung cancer [15]. The current study explored association between GAS5 rs145204276 and susceptibility of lung cancer using a case-control study in a Chinese population. We found the allele del was significantly associated with $21 \%$ decreased risk of lung cancer $(\mathrm{OR}=0.79 ; 95 \% \mathrm{CI}=0.66-0.93$; $\mathrm{P}$ value $=0.006$ ). To the best of our knowledge, this should be first study which evaluated the genetic association of GAS5 with the susceptibility of lung cancer.

GAS5, whose transcriptional unit is divided into 12 exons that span around $7 \mathrm{~kb}$, was first isolated from mouse genomic DNA by Coccia et al in 1992 [16]. Then Fleming et al detected it was expressed in the mouse preimplantation embryo [17]. Mourtada-Maarabouni et al first identified that GAS5 transcripts were subject to complex post-transcriptional processing, could controls apoptosis and was down regulated in breast cancer [18]. Furthermore, Liu et al found that down regulation of GAS5 promotes bladder cancer cell proliferation, partly by regulating CDK6 [19]. Lu et al also revealed that down regulation of gas 5 increases pancreatic cancer cell proliferation by regulating CDK6 [20]. Subsequently, gas5 was identified as a tumor suppressor, and prognosis marker in renal cell carcinoma, cervical cancer, malignant pleural mesothelioma, gastric cancer, colorectal cancer, endometrial cancer, and breast cancer [11, 21-29]. Mazar, $\mathrm{J}$ et al [30] found differentially regulates cell cycle arrest and apoptosis through activation of BRCA1 and p53 in human neuroblastoma. However, only two studies evaluated associations of the genetic variation of lncRNA GAS5 with cancers (colorectal cancer and hepatocellular carcinoma), which raised the concern of the differential roles of lncRNA GAS5 in the carcinogenesis progress of different cancer types $[10,13]$.

In current study, we found the del allele of GAS5 rs 145204276 was significantly associated with decreased risk of lung cancer with a statistical power of $77 \%$. Combined with the results of real-time PCR analysis that the expression levels of lncRNA GAS5 in lung cancer tissues were significantly lower than those in the corresponding normal tissues and the relative GAS5 expression level in samples with del/del genotype was significantly higher than that in samples with ins/del and ins/ins genotype, we can conclude that GAS5 functions as a tumor suppressor in lung cancer, and rs145204276 could increase the expression of lncRNA GAS5 in tissues. These findings were consistent with results of Zheng et al in colorectal cancer, which also showed that the carriers of allele del are less likely to get lymph node metastasis [10].

Our study had its own advantages. First, the moderate sample size was enrolled in current 
Table 1: Distributions of selected variables in lung cancer cases and cancer-free controls

\begin{tabular}{|c|c|c|c|}
\hline & Cases $(n=600)$ & Controls $(n=600)$ & P value \\
\hline \multicolumn{4}{|l|}{ Age } \\
\hline$<60$ & $239(39.8 \%)$ & $231(38.5 \%)$ & 0.620 \\
\hline$\geq 60$ & $361(60.2 \%)$ & $369(61.5 \%)$ & \\
\hline \multicolumn{4}{|l|}{ Gender } \\
\hline Male & $425(70.8 \%)$ & $419(69.8 \%)$ & 0.691 \\
\hline female & $175(29.2 \%)$ & $181(30.2 \%)$ & \\
\hline \multicolumn{4}{|l|}{ Smoking status } \\
\hline Ever & $218(36.3 \%)$ & $126(21.0 \%)$ & $P<0.001$ \\
\hline Never & $382(63.2 \%)$ & $474(79.0 \%)$ & \\
\hline \multicolumn{4}{|l|}{ Histology } \\
\hline Adenocarcinoma & $231(38.5 \%)$ & & \\
\hline Squamous cell & $369(61.5 \%)$ & & \\
\hline
\end{tabular}

Table 2: Associations between GAS5 rs145204276 and lung cancer susceptibility

\begin{tabular}{|c|c|c|c|c|c|}
\hline Genetic model & Genotype & Cases & Controls & OR $(95 \% \text { CI })^{a}$ & P value \\
\hline \multirow[t]{3}{*}{ Codominant model } & ins/ins & 287 & 246 & 1.00 (Reference) & \\
\hline & ins/del & 270 & 292 & $0.78(0.62-0.99)$ & 0.044 \\
\hline & $\mathrm{del} / \mathrm{del}$ & 43 & 62 & $0.59(0.39-0.89)$ & 0.011 \\
\hline \multirow[t]{2}{*}{ Dominant model } & ins/ins & 287 & 246 & 1.00 (Reference) & \\
\hline & ins/del + del/del & 313 & 354 & $0.75(0.60-0.984)$ & 0.012 \\
\hline \multirow[t]{2}{*}{ Recessive model } & ins/ins + ins/del & 557 & 538 & 1.00 (Reference) & \\
\hline & del/del & 43 & 62 & $0.66(0.45-0.98)$ & 0.042 \\
\hline \multirow[t]{2}{*}{ Additive model } & ins allele & & & 1.00 (Reference) & \\
\hline & del allele & & & $0.79(0.66-0.93)$ & 0.006 \\
\hline
\end{tabular}

${ }^{\text {a }}$ Adjusted for age, gender, and smoking status.

A

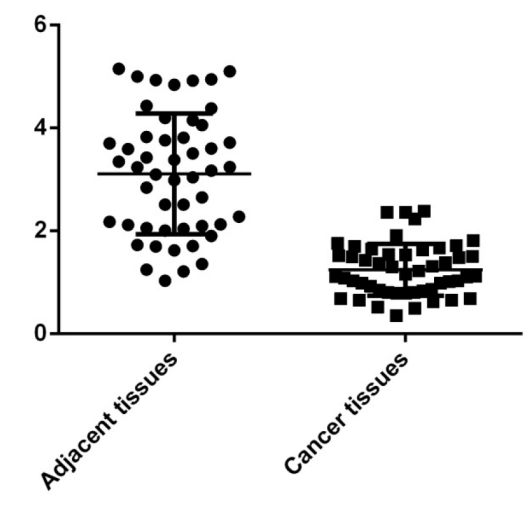

B

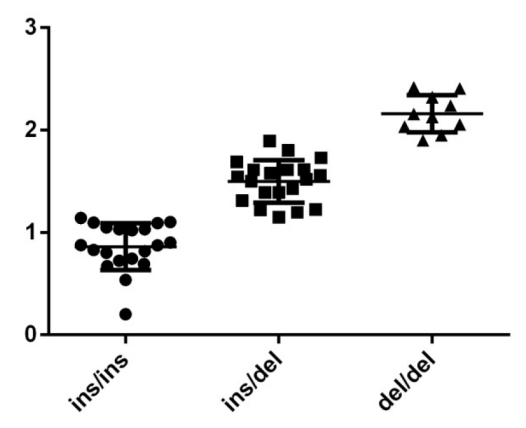

Figure 1: Relative expression of GAS5. 
study; second, we characterized the function of SNP rs145204276, making the association of this SNP with the risk of lung cancer biological plausible. Despite of these strengths mentioned above, some limitations should be noted. Limited information of further evaluation of gene-environment interactions, deficiency of independent replication, and unavoidable selection bias for case-control study. However, we still provide strong evidence for the tumor suppressor role of lncRNA GAS5. In summary, we demonstrated that SNP rs145204276 of GAS5was associated with decreased risk of lung cancer in the Chinese populations. These findings should be verified by larger, well-designed epidemiologic and functional studies.

\section{PATIENTS AND METHODS}

\section{Study subjects}

In current study, we enrolled 600 incident cases of lung cancer, and 600 healthy controls, which were matched by age and gender. The diagnosis of patients was validated through pathologic examination by two different senior pathologists, while healthy controls free of any type cancers were selected from the neighboring area with the similar life, diet habits, and environmental exposure. After signing informed consent, we collected $5 \mathrm{ml}$ venous blood from each patient and took a face-to-face interview with a standard questionnaire including information on demographic data.

\section{DNA extraction and genotyping}

we extracted genomic DNA from peripheral blood using phenol chloroform extraction. DNA fragments containing the indel polymorphism were amplified using genotyping primers: F-TCCCGACTGAGGAGGAAGAGCA; R-AACACCG TCCCGGAAGTGAAA. Participants' status was unrevealed in the genotyping process. For quality control, two duplicated samples were included in each 384-plate for the quality control. The assays were repeated for $5 \%$ of the samples, and the results were $100 \%$ concordant.

\section{Real-time PCR analysis}

Total RNA from lung cancer and adjacent tissue samples with different genotypes was extracted according to the manufacturer's protocol (Invitrogen, Carlsbad, CA, USA). SYBR Green real-time PCR (reverse transcriptasePCR) was performed on Roche Light Cycler 480 system to quantify relative GAS5 expression in these samples. Glyceraldehyde 3-phosphate dehydrogenase (GAPDH) was used as an internal control. The assay was conducted using the ABI 7300 system (Applied Biosystems). The $2^{-\triangle \Delta C T}$ algorithm was applied to calculate the expression levels for different groups.

\section{Statistical analysis}

All the statistical analyses were two-sided and were performed with the SAS 9.2 software (SAS Institute, Cary, NC, USA), while $\mathrm{P}$ value $<0.05$ was considered statistically significant. The associations between GAS5 rs145204276 and risk of lung cancer were evaluated by odds ratios (ORs) and their 95\% confidence intervals (CIs) from unconditional logistic regression analyses. Chi-square $(\chi 2)$ test was used to estimate the distribution differences of demographic characteristics as well as genotypes and alleles of the rs 145204276 between cases and controls. All ORs were adjusted for age, gender, and smoking status. Hardy-Weinberg equilibrium (HWE) was tested using a goodness-of-ft $\chi 2$-test.

\section{CONFLICTS OF INTEREST}

The authors declare that they have no conflicts of interest.

\section{REFERENCES}

1. Torre LA, Bray F, Siegel RL, Ferlay J, Lortet-Tieulent J, Jemal A. Global cancer statistics, 2012. CA Cancer J Clin. 2015; 65:87-108.

2. Torre LA, Siegel RL, Jemal A. Lung cancer statistics. Adv Exp Med Biol. 2016; 893:1-19.

3. Thill PG, Goswami P, Berchem G, Domon B. Lung cancer statistics in Luxembourg from 1981 to 2008. Bull Soc Sci Med Grand Duche Luxemb. 2011; 2:43-55.

4. Zheng R, Zeng H, Zhang S, Chen T, Chen W. National estimates of cancer prevalence in China, 2011. Cancer Lett. 2016; 370:33-38.

5. Chen W, Zheng R, Baade PD, Zhang S, Zeng H, Bray F, Jemal A, Yu XQ, He J. Cancer statistics in China, 2015. CA Cancer J Clin. 2016; 66:115-132.

6. Chang ET, Liu Z, Hildesheim A, Liu Q, Cai Y, Zhang Z, Chen G, Xie SH, Cao SM, Shao JY, Jia WH, Zheng $\mathrm{Y}$, Liao J, et al. Active and passive smoking and risk of nasopharyngeal carcinoma: a population-based case-control study in Southern China. Am J Epidemiol. 2017:1-9.

7. Fu H, Feng D, Tang S, He Z, Xiang Y, Wu T, Wang R, Shao T, Liu C, Shao P, Feng Z. Prevalence of tobacco smoking and determinants of success in quitting smoking among patients with chronic diseases: a cross-sectional study in rural western China. Int J Environ Res Public Health. 2017; 14:167.

8. Xia S, Ji R, Zhan W. Long noncoding RNA papillary thyroid carcinoma susceptibility candidate 3 (PTCSC3) inhibits proliferation and invasion of glioma cells by suppressing the Wnt/beta-catenin signaling pathway. BMC Neurol. 2017; 17:30.

9. Zhou X, Chen H, Zhu L, Hao B, Zhang W, Hua J, Gu H, Jin W, Zhang G. Helicobacter pylori infection related long 
noncoding RNA (lncRNA) AF147447 inhibits gastric cancer proliferation and invasion by targeting MUC2 and up-regulating miR-34c. Oncotarget. 2016; 7:82770-82782. https://doi.org/10.18632/oncotarget.13165.

10. Zheng Y, Song D, Xiao K, Yang C, Ding Y, Deng W, Tong S. LncRNA GAS5 contributes to lymphatic metastasis in colorectal cancer. Oncotarget. 2016; 7:83727-83734. https:// doi.org/10.18632/oncotarget.13384.

11. Pickard MR, Williams GT. The hormone response element mimic sequence of GAS5 lncRNA is sufficient to induce apoptosis in breast cancer cells. Oncotarget. 2016; 7:1010410116. https://doi.org/10.18632/oncotarget.7173.

12. Ma C, Shi X, Zhu Q, Li Q, Liu Y, Yao Y, Song Y. The growth arrest-specific transcript 5 (GAS5): a pivotal tumor suppressor long noncoding RNA in human cancers. Tumour Biol. 2016; 37:1437-1444.

13. Tao R, Hu S, Wang S, Zhou X, Zhang Q, Wang C, Zhao X, Zhou W, Zhang S, Li C, Zhao H, He Y, Zhu S, et al. Association between indel polymorphism in the promoter region of lncRNA GAS5 and the risk of hepatocellular carcinoma. Carcinogenesis. 2015; 36:1136-1143.

14. Song W, Wang K, Zhang RJ, Dai QX, Zou SB. Long noncoding RNA GAS5 can predict metastasis and poor prognosis: a meta-analysis. Minerva Med. 2016; 107:70-76.

15. Liang W, Lv T, Shi X, Liu H, Zhu Q, Zeng J, Yang W, Yin J, Song Y. Circulating long noncoding RNA GAS5 is a novel biomarker for the diagnosis of nonsmall cell lung cancer. Medicine (Baltimore). 2016; 95:e4608.

16. Coccia EM, Cicala C, Charlesworth A, Ciccarelli C, Rossi GB, Philipson L, Sorrentino V. Regulation and expression of a growth arrest-specific gene (gas5) during growth, differentiation, and development. Mol Cell Biol. 1992; 12:3514-3521.

17. Fleming JV, Fontanier N, Harries DN, Rees WD. The growth arrest genes gas5, gas6, and CHOP-10 (gadd153) are expressed in the mouse preimplantation embryo. Mol Reprod Dev. 1997; 48:310-316.

18. Mourtada-Maarabouni M, Pickard MR, Hedge VL, Farzaneh F, Williams GT. GAS5, a non-protein-coding RNA, controls apoptosis and is downregulated in breast cancer. Oncogene. 2009; 28:195-208.

19. Liu Z, Wang W, Jiang J, Bao E, Xu D, Zeng Y, Tao L, Qiu J. Downregulation of GAS5 promotes bladder cancer cell proliferation, partly by regulating CDK6. PLoS One. 2013; 8:e73991.
20. Lu X, Fang Y, Wang Z, Xie J, Zhan Q, Deng X, Chen H, Jin J, Peng C, Li H, Shen B. Downregulation of gas5 increases pancreatic cancer cell proliferation by regulating CDK6. Cell Tissue Res. 2013; 354:891-896.

21. Qiao HP, Gao WS, Huo JX, Yang ZS. Long non-coding RNA GAS5 functions as a tumor suppressor in renal cell carcinoma. Asian Pac J Cancer Prev. 2013; 14:1077-1082.

22. Cao S, Liu W, Li F, Zhao W, Qin C. Decreased expression of lncRNA GAS5 predicts a poor prognosis in cervical cancer. Int J Clin Exp Pathol. 2014; 7:6776-6783.

23. Renganathan A, Kresoja-Rakic J, Echeverry N, Ziltener G, Vrugt B, Opitz I, Stahel RA, Felley-Bosco E. GAS5 long non-coding RNA in malignant pleural mesothelioma. Mol Cancer. 2014; 13:119.

24. Sun M, Jin FY, Xia R, Kong R, Li JH, Xu TP, Liu YW, Zhang EB, Liu XH, De W. Decreased expression of long noncoding RNA GAS5 indicates a poor prognosis and promotes cell proliferation in gastric cancer. BMC Cancer. 2014; $14: 319$.

25. Yin D, He X, Zhang E, Kong R, De W, Zhang Z. Long noncoding RNA GAS5 affects cell proliferation and predicts a poor prognosis in patients with colorectal cancer. Med Oncol. 2014; 31:253.

26. Guo C, Song WQ, Sun P, Jin L, Dai HY. LncRNA-GAS5 induces PTEN expression through inhibiting miR-103 in endometrial cancer cells. J Biomed Sci. 2015; 22:100.

27. Guo X, Deng K, Wang H, Xia J, Shan T, Liang Z, Yao L, Jin S. GAS5 inhibits gastric cancer cell proliferation partly by modulating CDK6. Oncol Res Treat. 2015; 38:362-366.

28. Han L, Ma P, Liu SM, Zhou X. Circulating long noncoding RNA GAS5 as a potential biomarker in breast cancer for assessing the surgical effects. Tumour Biol. 2016; 37:6847-6854.

29. Li W, Zhai L, Wang H, Liu C, Zhang J, Chen W, Wei Q. Downregulation of LncRNA GAS5 causes trastuzumab resistance in breast cancer. Oncotarget. 2016; 7:2777827786. https://doi,org/410.18632/oncotarget.8413.

30. Mazar J, Rosado A, Shelley J, Marchica J, Westmoreland TJ. The long non-coding RNA GAS5 differentially regulates cell cycle arrest and apoptosis through activation of BRCA1 and p53 in human neuroblastoma. Oncotarget. 2017; 8:6589-6607. https://doi.org/10.18632/oncotarget.14244. 